\title{
The Adrenomedullary and Glucagon Responses of Hypopituitary Children to Insulin-Induced Hypoglycemia
}

\author{
MARY L. VOORHESS, ${ }^{(26)}$ AUDREY F. JAKUBOWSKI, AND MARGARET H. MACGILLIVRAY \\ Department of Pediatrics, State University of New York at Buffalo School of Medicine, and The Children's Hospital \\ of Buffalo, Buffalo, New York, USA
}

\begin{abstract}
Summary
The activity of phenyl- $N$-methyl transferase (PNMT), the adrenomedullary enzyme which catalyzes the $N$-methylation of norepinephrine (NE) to epinephrine (E) is induced by endogenous glucocorticoid hormones secreted by the adrenal cortex. We quantitated the urinary output of $\mathrm{NE}$ and $\mathrm{E}$ before, during, and after insulin-induced hypoglycemia in patients with pituitary dysfunction. Plasma concentrations of cortisol, growth hormone, and glucagon were measured simultaneously. The study population was comprised of nine healthy controls (group 1), eight children with growth hormone deficiency (group 2), and eight children with combined growth hormone and cortisol deficiencies (group 3). Recovery from acute hypoglycemia was similar in all groups. Mean plasma glucagon values reached a maximum at $30 \mathrm{~min}$ after insulin injection, and no significant differences were observed among the groups. Plasma cortisol levels were similar in groups 1 and 2 , maximum values ocurring at $45 \mathrm{~min}$ after insulin. Patients in group 3 did not increase their cortisol concentrations above $5.5 \mu \mathrm{g} / \mathrm{d}$ despite a greater than $50 \%$ drop in blood glucose. Mean urinary $\mathrm{E}$ output of all groups increased significantly above pretest values (groups 1 and $2, P<0.001$; and group $3, P<0.01$ ), whereas $N E$ levels were unchanged. After hypoglycemia, the mean $E$ increments in the control and cortisol-deficient groups were not significantly different.

The data can be interpreted in two ways. Endogenous cortisol production in ACTH-deficient hypopituitary children is sufficient to maintain PNMT activity at a level needed for synthesis of $E$ from NE. Alternatively, cortisol may not be essential for $\mathbf{E}$ release during acute hypoglycemia because hypothalamic regulatory mechanisms supervene, and direct neural stimulation promotes PNMT activity and synthesis of $E$.

We conclude that patients with cortisol and growth hormone deficiencies are able to recover from acute hypoglycemia when hepatic glycogen stores are adequate because there is sufficient release of $\mathbf{E}$ or because other adrenergic mechanisms stimulate glucagon release and hepatic glycogenolysis.
\end{abstract}

\section{Speculation}

Although children with cortisol and growth hormone deficiencies are able to recover from acute hypoglycemia, many do not tolerate a prolonged fast because of diminished gluconeogenesis and depletion of hepatic glycogen.

Studies in animals have shown that the activity of phenylethanolamine- $N$-methyl transferase (PNMT), the adrenomedullary enzyme which catalyzes the $\mathbf{N}$-methylation of norepinephrine (NE) to epinephrine (E), is induced by endogenous glucocorticoid hormones secreted by the adrenal cortex. Hypophysectomy in rats and dogs is followed by a prompt decline in PNMT activity and in E synthesis which can be restored by administration of ACTH. Treatment with large doses of glucocorticoid also restores PNMT whereas physiologic doses of dexamethasone, corticosteroid, and hydrocortisone are ineffective, probably because their intramedullary concentration is insufficient for enzyme induction $(12,22$, 23).

Few investigations concerning the influence of ACTH and glucocorticoid hormones on epinephrine synthesis have been performed in man $(3,10,13-15)$. On the basis of the animal experiments, we theorized that children with decreased cortisol production from ACTH deficiency secondary to hypothalamic-pituitary disorders might have impaired $E$ synthesis and abnormalities of carbohydrate homeostasis. To test this hypothesis, we quantitated the urinary catecholamine output before, during, and after insulin induced hypoglycemia in patients with pituitary dysfunction. The plasma concentrations. of the other major counterregulatory hormones were measured simultaneously. The results of these studies are described in this report.

\section{EXPERIMENTAL SUBJECTS}

Twenty-five children with short stature who were suspected of having growth hormone deficiency alone or combined with deficiencies of other anterior pituitary hormones comprised the study population. None had a history of hypoglycemia. Each child had been eating a regular diet at home, and no one received special dietary preparation before testing. All were clinically and biochemically euthyroid. Those with thyroid-stimulating hormone deficiency were receiving 1-thyroxine therapy and had normal serum $T_{4}$, levels. Each was admitted to the Metabolic Unit of Buffalo Children's Hospital for evaluation of their hypothalamicpituitary-adrenal axis according to a protocol which had been approved by the Institutional Review Board. Written informed consent was obtained from patients and/or parents before each study.

Clinical data about the participants are listed in Table 1.

\section{MATERIALS AND METHODS}

\section{ARGININE STIMULATION TEST}

After an overnight fast beginning at $2100 \mathrm{hr}$, arginine, $0.5 \mathrm{~g} / \mathrm{kg}$ body weight was given intravenously over $30 \mathrm{~min}$ starting at 0800 . Plasma samples were collected at $-30,-15,0+15,30,45,60,120$ min for growth hormone analysis.

\section{INSULIN-INDUCED HYPOGLYCEMIA}

After a similar overnight fast, a bolus injection of regular insulin, 0.05 to $0.08 \mathrm{units} / \mathrm{kg}$ body weight was given intravenously at $0800 \mathrm{hr}$. Studies were considered valid when the blood glucose level dropped to less than $50 \%$ of the baseline value. Samples of 
Table 1. Data about the study population ${ }^{1}$

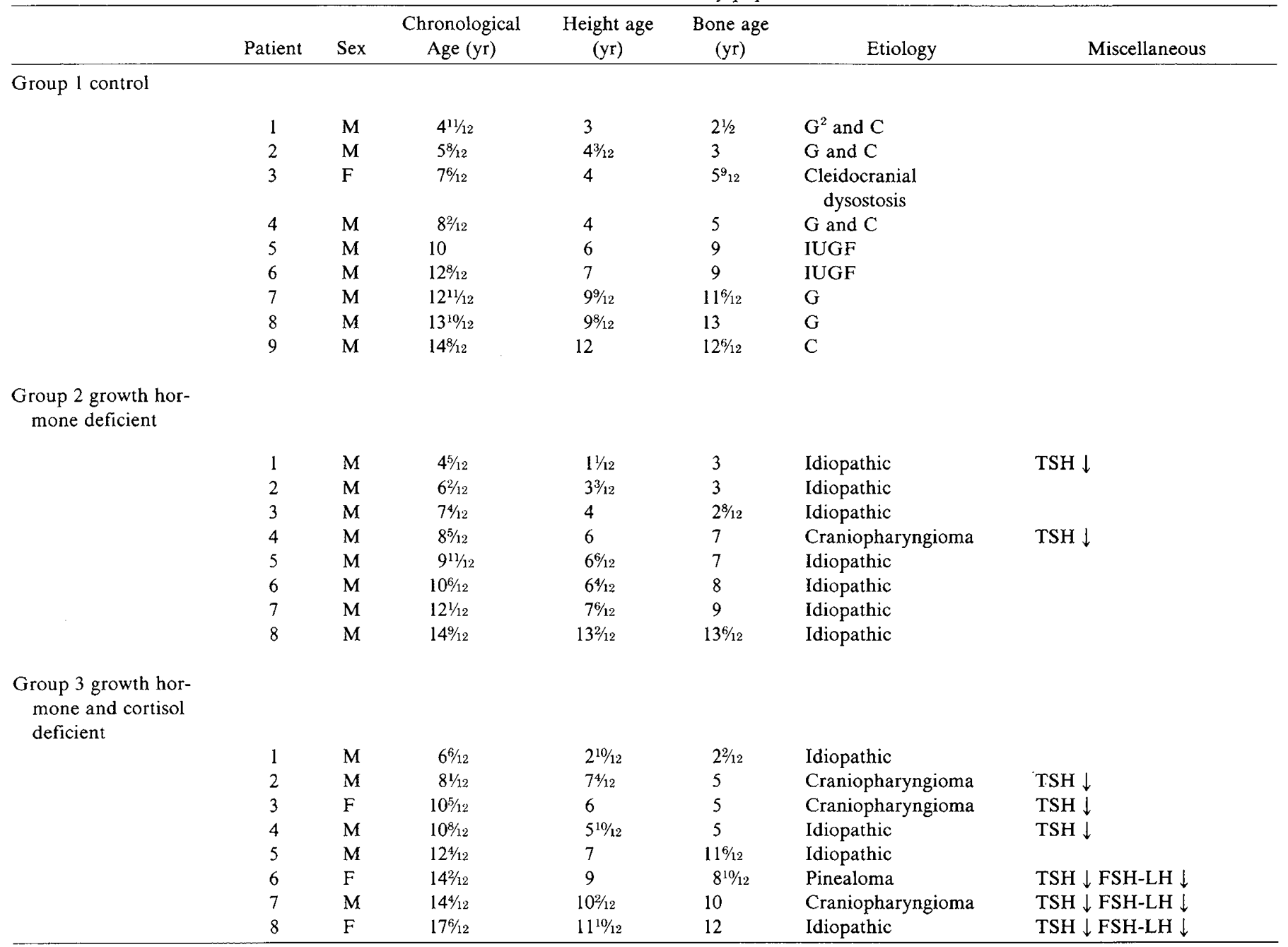

\footnotetext{
' Children with thyroid stimulating hormone deficiency (TSH $\downarrow$ ) were euthyroid on 1-thyroxine therapy. Children with gonadotropin deficiencies (FSH-LH $\downarrow$ ) were not receiving sex steroids.

${ }^{2} \mathrm{G}$, genetic short stature; C, constitutional delay; IUGF, intrauterine growth failure; TSH, thyroid-stimulating hormone.
}

plasma were obtained at $-30,-15,0,+15,30,45,60,90$, and 120 min and were assayed for glucose, glucagon, growth hormone, and cortisol concentrations. Glucose levels also were determined at +20 and +25 min.

Consecutive timed urine specimens were collected before $(0530$ to $0800 \mathrm{hr}$ ), during (0800 to $1000 \mathrm{hr})$, and after $(1000$ to $1130 \mathrm{hr})$ acute hypoglycemia and analyzed for NE and $\mathrm{E}$. This study design was chosen because measurement of urinary free $E$ levels provides an integrated assessment of production over a specific time period and allows for comparison of baseline $E$ excretion with the output during hypoglycemia. Recent studies in our laboratory have shown that both urinary $E$ output and plasma $E$ concentration increase 4 to 20 times in response to insulin hypoglycemia. Urinary free NE levels, however, may not reflect sympathetic activity because of rapid reuptake of this amine into nerve endings.

The glucose oxidase method was used for quantitation of blood glucose. Plasma growth hormone was measured by double antibody radioimmunoassay techniques $(1,7)$. Plasma corticoid was determined by the competitive protein binding method of Murphy (16). Antiglucagon antisera ( $30 \mathrm{~K})$, purchased from Dr. R. Unger, was used to assay plasma glucagon according to the method of Faloona and Unger (8) except double antibody precipitation was substituted for charcoal dextran separation. Urinary free NE and E were analyzed by spectrophotofluoremetry using previously described techniques (20).

The data were analyzed using the Student $t$ test.

\section{RESULTS}

\section{CLASSIFICATION OF PATIENTS}

The patients were divided into three groups based on their growth hormone and cortisol responses to arginine and to insulininduced hypoglycemia.

Group 1: Nine children-control population

Peak plasma growth hormone, $>8 \mathrm{ng} / \mathrm{ml}$

Baseline plasma cortisol, $>8 \mu \mathrm{g} / \mathrm{dl}$

Peak poststimulation plasma cortisol, $>16 \mu \mathrm{g} / \mathrm{dl}$

Group 2: Eight children-growth hormone deficient and cortisol sufficient

Peak plasma growth hormone, $<4 \mathrm{ng} / \mathrm{ml}$

Baseline plasma cortisol,' $>8 \mu \mathrm{g} / \mathrm{dl}$

Peak poststimulation plasma cortisol, $>16 \mu \mathrm{g} / \mathrm{dl}$

Group 3: Eight children-growth hormone and cortisol deficient

Peak plasma growth hormone, $<4 \mu \mathrm{g} / \mathrm{ml}$

Baseline plasma cortisol, $<6 \mu \mathrm{g} / \mathrm{dl}$

Peak poststimulation plasma cortisol, $<6 \mu \mathrm{g} / \mathrm{dl}$

\section{BLOOD GLUCOSE}

Mean fasting blood glucose levels were higher in the control children $(P<0.03$ at $-15 \mathrm{~min})$. After insulin administration, there was a rapid fall in glucose levels in all patients with the nadir 
Table 2. Glucagon responses to insulin hypoglycemia $(\mathrm{pg} / \mathrm{ml})$

\begin{tabular}{ccccccrrrr}
\hline & \multicolumn{7}{c}{ Time } \\
\cline { 2 - 8 } Group & \multicolumn{1}{c}{-30} & 0 & \multicolumn{1}{c}{+15} & 20 & 30 & 45 & 60 & 90 \\
\hline 1 & $73 \pm 13^{1}$ & $68 \pm 13$ & $92 \pm 14$ & $475 \pm 52$ & $165 \pm 26$ & $91 \pm 20$ & $87 \pm 18$ & $87 \pm 13$ & $108 \pm 23$ \\
2 & $108 \pm 30$ & $87 \pm 19$ & $92 \pm 19$ & $125 \pm 21$ & $188 \pm 23$ & $148 \pm 21$ & $125 \pm 33$ & $77 \pm 18$ & $116 \pm 27$ \\
3 & $105 \pm 33$ & $72 \pm 17$ & $184 \pm 47$ & $152 \pm 39$ & $248 \pm 85$ & $109 \pm 20$ & $50 \pm 19$ & $59 \pm 23$ & $74 \pm 25$ \\
\hline
\end{tabular}

${ }^{1}$ Mean \pm S.E.

\section{Plasma Glucose During Insulin-Induced Hypoglycemia(mean—SEM)}

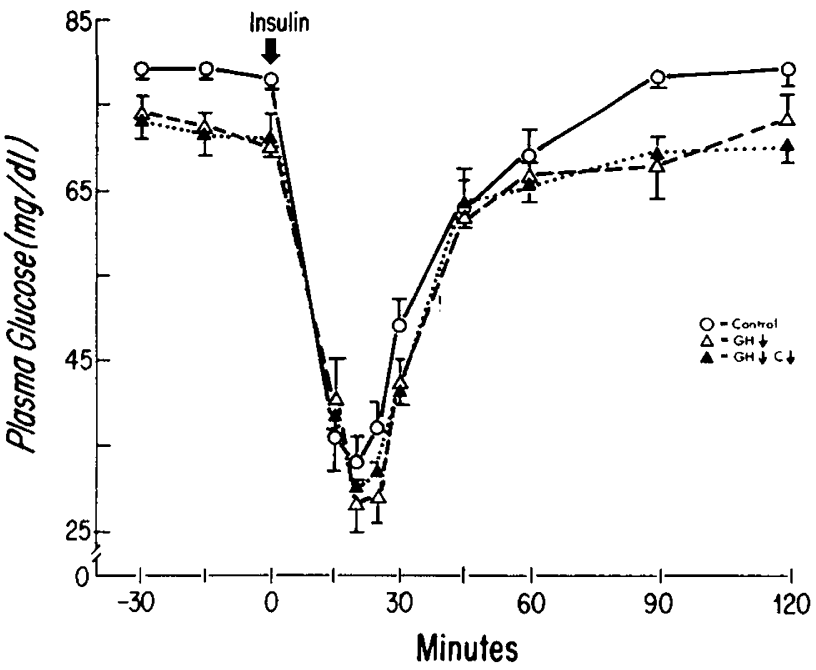

Fig. 1. Mean plasma glucose concentrations ( \pm S.E.) of control subjects, growth hormone-deficient patients ( $G H \downarrow$ ), and patients with combined growth hormone and cortisol deficiencies $(G H \downarrow C \downarrow)$ in response to insulin-induced hypoglycemia. Insulin given intravenously at time " 0 ."

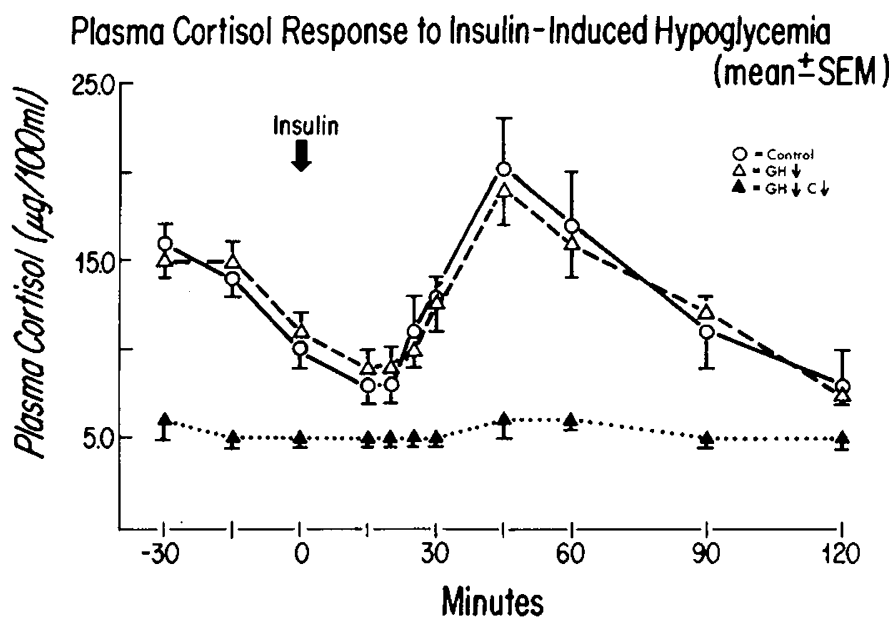

Fig. 2. Mean plasma cortisol concentrations ( \pm S.E.) of control subjects, growth hormone-deficient patients ( $G H \downarrow$ ), and patients with combined growth hormone and cortisol deficiencies $(G H \downarrow C \downarrow)$ in response to insulin-induced hypoglycemia. Insulin given intravenously at time " 0 ."

usually occurring at $20 \mathrm{~min}$. There were no significant differences between the groups even though patients in group 1 received 0.08 unit $/ \mathrm{kg}$ regular insulin whereas those in group 2 and 3 were given only $0.05 \mathrm{unit} / \mathrm{kg}$ regular insulin as a bolus intravenous injection. Recovery from hypoglycemia was similar in all groups, and baseline glucose levels were reached at about $90 \mathrm{~min}$ after insulin administration (Fig. 1).

\section{GLUCAGON}

Mean plasma glucagon values reached a maximum at $30 \mathrm{~min}$ after insulin injection (Table 2) and returned to baseline concen-

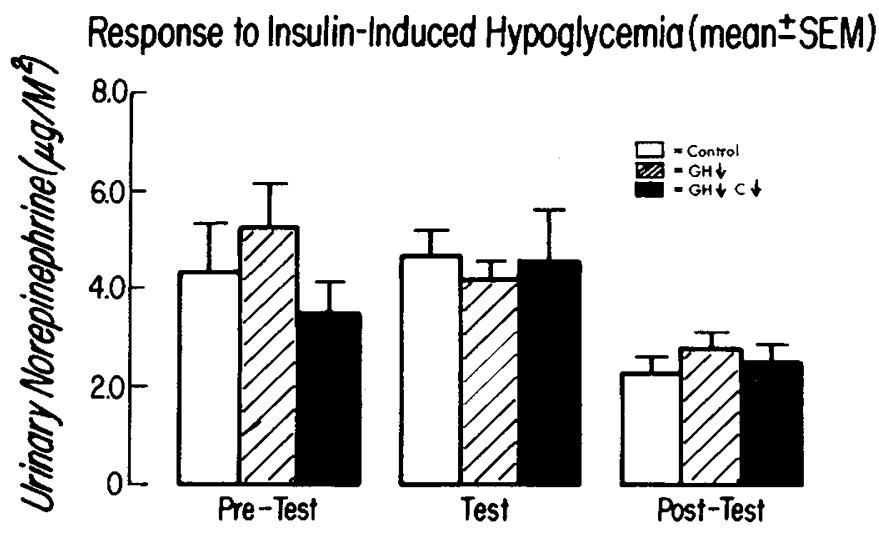

Fig. 3. Mean urinary norepinephrine levels in timed urine specimens collected before, during, and after insulin-induced hypoglycemia. Specimens were collected from control subjects, patients with growth hormone deficiency $(G H \downarrow)$, and patients with combined growth hormone and cortisol deficiencies $(G H \downarrow C \downarrow)$.

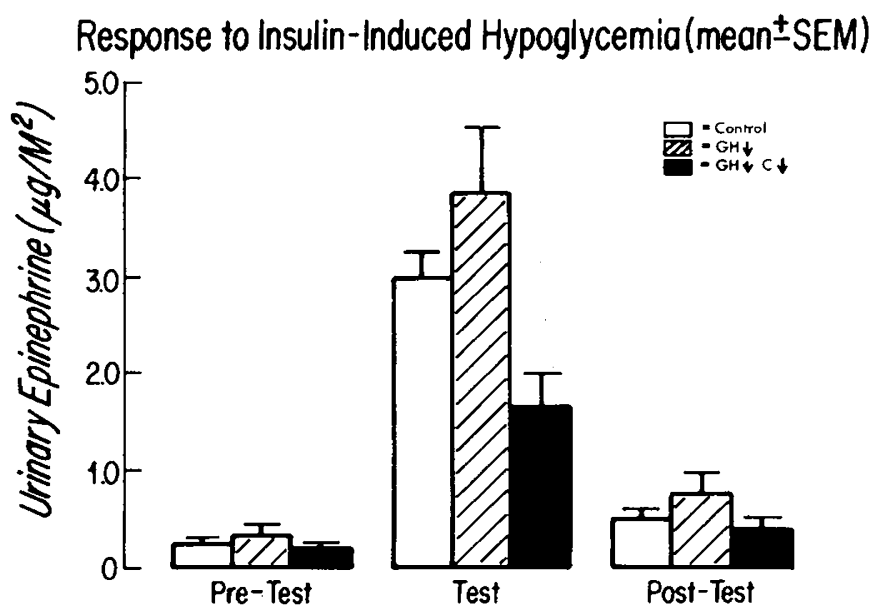

Fig. 4. Mean urinary $E$ levels in timed urine specimens collected before, during, and after insulin-induced hypoglycemia. Specimens were collected from control subjects, patients with growth-hormone deficiency ( $\mathrm{GH} \downarrow$ ), and patients with combined growth hormone and cortisol deficiencies $(G H \downarrow C \downarrow)$.

trations by 60 to $90 \mathrm{~min}$. No significant differences were observed among the groups.

\section{CORTISOL}

Cortisol levels were similar among members of groups 1 and 2, maximum values occurring at $+45 \mathrm{~min}$ after insulin administration (Fig. 2). Patients in group 3 did not increase their cortisol concentrations above baseline despite a greater than $50 \%$ drop in blood glucose.

\section{CATECHOLAMINES}

Following insulin-induced hypoglycemia, the mean E output of all groups increased significantly above pretest values (groups 1 and $2, P<0.001$, and group $3, P<0.01$ ) whereas NE levels were unchanged (Figs. 3 and 4). Groups 1 and 2 increased their urinary 
E output 12- to 13-fold as compared to an 8-fold increase in group 3. The mean $\mathrm{E}$ increment between the control and cortisol-deficient groups was not significantly different $(P<0.1)$.

\section{DISCUSSION}

In this study, we observed that insulin-induced hypoglycemia provoked adrenomedullary responses and rates of glucose recovery which were not significantly different in healthy subjects (group 1), in patients with isolated growth hormone deficiency (group 2), or those with combined GH-ACTH-cortisol deficiency (group 3). Urinary E output increased 8-fold in the cortisol growth hormone-deficient children compared to a 12- to 13-fold increase in the control and growth hormone-deficient groups. The increments for both groups fall within the range reported in healthy children (5- to 20-fold increase in E). (2).

We had expected that ACTH deficiency in children would result in impaired E production because ACTH and glucocorticoid regulate the adrenomedullary enzyme, PNMT, which converts NE to E. No dysfunction in this pathway was detected with the acute hypoglycemic challenge used in this study.

Two mechanisms could account for the adequate release of $\mathrm{E}$ in ACTH-cortisol-deficient children. First, it is possible that endogenous cortisol production was sufficient to maintain PNMT activity at the level needed for synthesis of $E$ from NE. Little information is available concerning the quantity of glucocorticoid required for this function in man. Kitabchi and Williams (11) measured PNMT activity in human adrenals, but they could demonstrate no correlation between enzyme activity and the high concentration of ACTH or glucocorticoid which occurs in Cushing's syndrome. We have not found any published measurements of PNMT activity in glucocorticoid-deficient human adrenals. However, hypophysectomized rats have shown reduced levels of PNMT activity but still retain their ability to synthesize epinephrine, albeit, at a depressed rate (21).

Second, cortisol may not be the sole mediator of PNMT synthesis. Support for this possibility comes from the studies of Theonen et al. (19) which suggest that the normal level of PNMT is maintained by adrenal glucocorticoids, whereas augmented PNMT activity is dependent on splanchnic nerve stimulation. Furthermore, Himsworth (9) has reported that chemoreceptors in the hypothalamus govern the secretion of $E$ in response to insufficient metabolizable glucose, and Stricker et al. (18) have shown that adrenal catecholamine secretion results from a decline in the availability of all utilizable fuels to the brain. Thus, cortisol may not be essential for $E$ release during acute hypoglycemia because hypothalamic regulatory mechanisms supervene and direct neural stimulation provokes discharge of $\mathrm{E}$.

Our study demonstrates that a rise in growth hormone and cortisol is not necessary for glucose recovery after acute hypoglycemia. Children deficient in both hormones (group 3) had glucose recovery rates comparable to the control and the growth hormonedeficient study population. Feldman et al. (5) also found that augmented secretion of cortisol and growth hormone is not required for restoration of normal plasma glucose concentration when they performed insulin tolerance tests on four normal volunteers whose cortisol and growth hormone secretion were reduced by cyproheptadine administration. They did not measure glucagon and catecholamines, however.

Glucagon appears to be a key hormone in restoration of normoglycemia after a sudden drop in blood glucose. This is supported in part by our studies in glucocorticoid-deficient hypopituitary children who are able to tolerate acute hypoglycemia. Normal glucagon and $\mathrm{E}$ production results in hepatic glycogenolysis and restoration of their glucose homeostasis provided glycogen stores are intact $(6,17)$. More conclusively, the importance of glucagon has been documented in adrenalectomized individuals who lack both cortisol and $\mathrm{E}$ and yet recover from acute glucopenia because of an appropriate alpha cell response (4).

\section{REFERENCES AND NOTES}

1. Achlach, D. S., and Parker, M. L.: A sensitive antibody immunoassay for human growth hormone in plasma. Nature (Lond.), 203: 1141 (1964).

2. Broberger, O., Jungner, I., and Zetterström, R.: Studies in spontaneous hypoglycemia in childhood. Failure to increase the epinephrine secretion in insulininduced hypoglycemia. J. Pediatr., 55: 713 (1959).

3. Duckworth, W. C., Masi, A. T., and Kitabchi, A. E.: Effect of low-dose cortisol therapy on epinephrine excretion in man. J. Clin. Endocrinol. Metab., 39: 750 (1974).

4. Ensinck, J. W., Walter, J. M., Palmer, J. R., Brodows, R. G., and Campbell, R. $\mathrm{G}$.: Glucagon responses to hypoglycemia in adrenalectomized man. Metabolism, 25: 227 (1976).

5. Feldman, J. M., Plonk, J. W., and Bivens, C. H.: The role of cortisol and growth hormone in the counter-regulation of insulin-induced hypoglycemia. Horm. Metab. Res., 7: 378 (1975).

6. Garber, A. J., Cryer, P. E., Santiago, J. V., Haymond, M., Pagliara, A. S., and Kipnis, D. M.: The role of adrenergic mechanisms in the substrate and hormonal response to insulin-induced hypoglycemia in man. J. Clin. Invest., 58: 7 (1976).

7. Greenwood, F. G., Hunter. W. M., and Glover, J. S.: The preparation of I-131 labeled human growth hormone in high specific radioactivity. Biochem. J., 89: 114 (1963)

8. Faloona, G. R., and Unger, R. H.: Glucagon. In: B. M. Jaffe, H. R. Behrman: Methods of Hormone Radioimmunoassay. pp. 317-330 (Academic Press, Inc., New York, 1974).

9. Himsworth, R. L.: Hypothalamic control of adrenaline excretion in response to insufficient glucose. J. Physiol (Lond.), 206: 411 (1970)

10. Hung, W., and Migeon, C. J.: Hypoglycemia in a two-year old boy with adrenocorticotropic hormone (ACTH) deficiency (probably isolated) and adrenal medullary unresponsiveness to insulin induced hypoglycemia. J. Clin. Endocrinol. Metab., 28: 146 (1968).

11. Kitabchi, A. E., and Williams, R. H.: Epinephrine synthesis in Cushing's syndrome. J. Clin. Endocrinol. Metab., 28: 1082 (1968).

12. Kvetnansky, R., Gerwirtz, G. P., Weise, V. K., and Kopin, I. J.: Effect of hypophysectomy on immobilization-induced elevation of tyrosine hydroxylase and phenylethanolamine- $N$-methyl transferase in the rat adrenal. Endocrinology, 87: 1323 (1970).

13. Luft, R., and von Euler, U. S.: Effect of insulin hypoglycemia on urinary excretion of adrenaline and noradrenaline in man after hypophysectomy. $\mathbf{J}$. Clin. Endocrinol. Metab., 16: 1017 (1956).

14. Morris, H. G., DeRoche, G., and Earle, M.: Effect of corticosteroid treatment on urinary epinephrine response in induced hypoglycemia in asthmatic children. J. Pharmacol. Exp. Therap., 184: 180 (1973).

15. Moyano, de G., Hauger-Klevene, J. H., Soto, R. G., and Bergada, C.: Effect of hypopituitarism and ACTH on urinary excretion of norepinephrine in man. $\mathbf{J}$. Clin. Endocrinol. Metab., 37: 1 (1973).

16. Murphy, B. E. P.: Some studies of the protein binding of steroids and their application to the routine micro and ultra micro measurement of various steroids in body fluids by competitive protein binding radioimmunoassay. $J$. Clin. Endocrinol. Metab., 27: 973 (1967).

17. Palmer, J. P., Henry, D. P., Benson, J. W., Johnson, D. G., and Esnick, J. W.: Glucagon response to hypoglycemia in sympathectomized man. J. Clin. Invest., 57: 522 (1976)

18. Stricker, E. M., Rowland, N., and Saller, C. F.: Homeostasis during hypoglycemia: central control of adrenal secretion and peripheral control of feeding. Science (Wash. D. C.), 196: 79 (1977).

19. Thoenen, H., Mueller, R. A., and Axelrod, A.: Neuronally dependent induction of adrenal phenylethanolamine- $N$-methyltransferase by 6 -hydroxydopamine. Biochem. Pharmacol., 19: 669 (1970).

20. Voorhess, M. L.: Urinary catecholamine excretion by healthy children: 1 . Daily excretion of dopamine, norepinephrine, epinephrine and 3-methoxy-4-hydroxy-mandelic acid. Pediatrics, 39: 252 (1967).

21. Wurtman, R. J.: Control of epinephrine synthesis in the adrenal medulla by the adrenal cortex: hormonal specificity and dose-response characteristics. Endocrinology, 79: 608 (1966).

22. Wurtman, R. J., Casper, A., Pohorecky, L. A., and Bartter, F. C.: Impaired secretion of epinephrine in response to insulin among hypophysectomized dogs. Proc. Nat1. Acad. Sci. U. S. A., 61: 522 (1968).

23. Wurtman, R. J., Pohorecky, and Baliga, B. S.: Adrenocortical control of the biosynthesis of epinephrine and proteins in the adrenal medulla. Pharmacol. Rev., 24: 411 (1972)

24. The pituitary hormones used in diagnostic testing and the growth hormone prescribed for treatment of the patients with growth hormone deficiency were provided by the National Pituitary Agency of the National Institute of Arthritis, Metabolism and Digestive Diseases.

25. The authors thank the Human Growth Foundation of Western New York, Susan T. Warren, Janet A. Ferrara, Miriam S. Link, Barbara A. Babcock, and Oleta M. Denz for their assistance with the study.

26. Requests for reprints should be addressed to: Mary L. Voorhess, M.D., Children's Hospital, 219 Bryant Street, Buffalo, NY 14222 (USA).

27. This research was supported in part by BRSG Grant RR-05493 awarded by the Biomedical Research Support Grant Program, Division of Research Resources, National Institutes of Health.

28. Received for publication July $15,1980$.

29. Accepted for publication October 2, 1980. 